\title{
PEMBENTUKAN DAN PELATIHAN KADER REMAJA PEDULI ASI (REMDULSI)
}

\author{
Aulia Fatmayanti'), Kuswanto'), Yanik Muyassaroh'), Anjar Astuti' ${ }^{4)}$, Marlynda \\ Happy Nurmalita Sari ${ }^{5}$ ) \\ Jurusan Kebidanan, Poltekkes Kemenkes semarang \\ auliafatmayanti@yahoo.com
}

\begin{abstract}
Background: Adolescents are one of the communities that can support the success of exclusive breastfeeding. Adolescents who are members of youth and youth groups can join in remdulsion (adolescents care about breast milk). The function of this group is to be able to help campaign for the success of exclusive breastfeeding and can also be a regeneration. To join the community and help the success of the exclusive breastfeeding campaign certainly requires good knowledge about breastfeeding in adolescents. During the preliminary survey, the servants interviewed 5 teenagers in the village of Karangjati. From the results of the interview, it was found that teenagers did not know about exclusive breastfeeding, including the benefits of breastfeeding, the limit of exclusive breastfeeding for infants and mothers.
\end{abstract}

Objective: Increase knowledge of cadre skills in providing counseling about ASI

Results: knowledge of adolescents increases after being given counseling through lecture methods and discussions.

Conclusion: Increased knowledge of Adolescents about Exclusive Breastfeeding.

Keywords: Adolescence, ASI, Remdulsion

\begin{abstract}
ABSTRAK
Latar Belakang : Remaja merupakan salah satu komunitas yang bisa mendukung suksesnya ASI eksklusif. Remaja yang tergabung dalam kelompok remaja dan karang taruna bisa bergabung dalam remdulsi (remaja peduli ASI). Fungsi dari kelompok ini adalah bisa membantu kampanye untuk keberhasilan ASI eksklusif dan juga bisa sebagai regenarasi. Untuk bergabung dalam komunitas tersebut dan membantu keberhasilan kampanye ASI eksklusif tentu diperlukan pengetahuan yang baik tentang ASI pada remaja. Pada saat survei pendahuluan, pengabdi melakukan wawancara kepada 5 remaja di desa Karangjati. Dari hasil wawancara tersebut diketahui bahwa remaja tidak mengetahui tentang ASI Eksklusif, termasuk manfaat ASI, batas pemberian ASI eksklusif pada bayi dan ibu.
\end{abstract}

Tujuan : Meningkatkan pengetahuan ketrampilan kader dalam memberikan penyuluhan tentang ASI.

Hasil : Pengetahuan remaja meningkat setelah di berikan penyuluhan melalui metode ceramah dan diskusi

Kesimpulan : Meningkatnya pengetahuan Remaja tentang ASI Eksklusif.

Kata kunci: ASI, Remaja, Remdulsi 


\section{PENDAHULUAN}

Remaja menurut Sulistyorini (2010) merupakan salah satu komunitas yang bisa mendukung suksesnya ASI eksklusif, remaja yang tergabung dalam kelompok remaja dan karang taruna bisa bergabung dalam remdulsi (remaja peduli ASI). Fungsi dari kelompok ini adalah bisa membantu kampanye untuk keberhasilan ASI eksklusif dan juga bisa sebagai regenarasi. Untuk bergabung dalam komunitas tersebut dan membantu keberhasilan kampanye ASI eksklusif tentu diperlukan pengetahuan yang baik tentang ASI pada remaja.

Batas usia remaja menurut Kumalasari dan Adhyantoro (2012) sesuai kesepakatan WHO adalah 10 - 20 tahun. Menurut Departemen Kesehatan, remaja adalah mereka yang berusia 10 19 tahun dan belum menikah.

Air Susu Ibu (ASI) merupakan nutrisi yang mengandung zat gizi yang cukup dan sangat penting untuk bayi. ASI mengandung zat kekebalan tubuh (immunologi) yang sangat dibutuhkan bayi agar tidak mudah sakit. Zat gizi yang terdapat di dalam ASI paling lengkap, sehingga ahli nutrisi bayi tidak ada yang bisa meniru membuat susu seperti yang ada kandungan semua zat gizi pada ASI. ASI penting bagi bayi karena manfaatnya tidak hanya untuk memenuhi kebutuhan nutrisi tetapi juga untuk kecerdasan bayi dan kesehatan bayi (Rahmi dalam Amatiria 2015).

Pada saat survei pendahuluan, pengabdi melakukan wawancara kepada 5 remaja di desa Karangjati. Dari hasil wawancara tersebut diketahui bahwa remaja tidak mengetahui tentang ASI Eksklusif, termasuk manfaat ASI, batas pemberian ASI eksklusif pada bayi dan manfaat kolustrum. Remaja juga tidak mengetahui tentang teknik menyusui yang baik dan benar terutama penyimpanan ASI untuk ibu bekerja.

Hal ini mendorong Prodi DIII Kebidanan Blora Poltekkes Kemenkes Semarang untuk melaksanakan kegiatan Pengabdian kepada Masyarakat (Pengabmas) berupa Pembentukan dan Pelatihan Kader Remaja ASI (Remdulsi) di Desa Karangjati Kecamatan Kota Blora Kabupaten Blora, sebagai bentuk dukungan terhadap program pemerintah di bidang kesehatan dan perwujudan Tri Dharma Perguruan Tinggi.

\section{METODE PELAKSANAAN}

Peserta yang mengikuti kegiatan pengabdian masyarakat ini sejumlah 15 remaja usia 1619 tahun, 1 orang bidan desa, 5 orang mahasiswa dan 4 orang dosen. Pada pelaksanaan kegiatan ini dibagi menjadi beberapa kegiatan yaitu kegiatan pembentukan dan pelatihan remaja peduli 
ASI dan monitoring evaluasi tentang praktik memotivasi ibu menyusui oleh kader Remdulsi. Metode pengbdian masyarakat ini meliputi alur kegiatan, tahapan kegiatan pengabmas yang akan dilaksanakan sebanyak 5x pertemuan, intervensi yang dilakukan dengan pemberian materi menggunakan power point, dan demonstrasi langsung menggunakan media. Adapun isi dari materi yang akan disampaikan yaitu Remdulsi dan ASI eksklusif. Evaluasi yang akan dilaksanakan yaitu tanya jawab dengan audience (remaja) setelah diberikan materi dan praktik dalam memberian penyuluhan (informasi) kepada ibu hamil menggunakan media serta post test diakhir kegiatan.

Kegiatan pengabdian masyarakat dilaksanakan di Kantor Kelurahan Karangjati pada tanggal 3 Agustus, 24 Agustus, 7 September, 12 Oktober dan 19 Oktober 2018. Pengabdian masyarakat ini menggunakan media power point dan modul Remdulsi, layar LCD, wireless, dan alat tulis. Pihak yang terlibat dalam kegiatan pengabdian masyarakat ini adalah dosen, mahasiswa, remaja, bidan desa, dan pihak Kelurahan Karangjati. Tolak ukur keberhasilan kegiatan ini adalah terbentuknya kader Remdulsi, meningkatnya pengetahuan dan kepedulian remaja untuk memotivasi ibu agar menyusui secara eksklusif serta adanya respon positif dari pihak terkait yang mengharapkan keberlanjutan kegiatan di waktu mendatang.

\section{HASIL DAN PEMBAHASAN}

Kegiatan pengabdian masyarakat Pembentukan dan Pelatihan Remaja Peduli ASI dihadiri oleh 15 remaja putri usia 16-19 tahun. Berikut adalah karakteristik peserta kegiatan pengabdian masyarakat:

Tabel 3.1 Karakteristik peserta kegiatan pengabmas berdasarkan tingkat pendidikan

\begin{tabular}{ccc}
\hline Tingkat pendidikan & $\mathrm{f}$ & $\%$ \\
\hline SMP & 7 & 46 \\
SMA & 8 & 54 \\
\hline Total & 10 & 100 \\
\hline
\end{tabular}

Sumber : data primer, 2018

Berdasarkan tabel 3.1 dapat diketahui bahwa sebagian besar responden berpendidikan SMA yaitu sebesar 54\%. 
Tabel 4.2 Perbedaan pengetahuan peserta pengabmas sebelum dan sesudah pemberian penyuluhan melalui metode ceramah dan diskusi

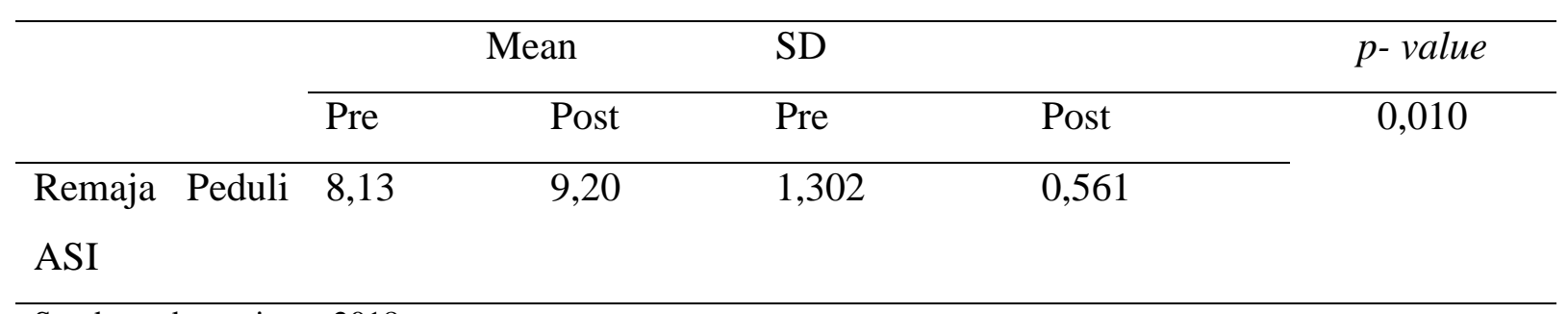

Sumber : data primer, 2018

Berdasarkan tabel 4.2 dapat diketahui bahwa pengetahuan remaja meningkat setelah di berikan penyuluhan melalui metode ceramah dan diskusi.

Pengetahuan seseorang bisa menjadi lebih luas dengan memiliki sumber informasi yang lebih banyak, seseorang akan cenderung untuk mendapatkan informasi, baik dari orang lain maupun dari media massa. Semakin banyak pengetahuan yang dimiliki maka akan mempengaruhi sikap dan ketrampilan kader. Hal ini sesuai dengan teori menurut Notoatmodjo (2012), salah satu faktor yang mempengaruhi pengetahuan seseorang adalah informasi. Informasi yang diperoleh dari petugas kesehatan dapat memberikan pengaruh jangka pendek sehingga menghasilkan perubahan atau peningkatan pengetahuan.

Dari hasil kegiatan pengabmas didapatkan bahwa telah terbentuk kader remaja peduli ASI (Remdulsi) sebanyak 15 orang dan pengetahuan remaja mengalami peningkatan setelah mendapatkan penyuluhan menggunakan metode ceramah dan demonstrasi. Pengetahuan peserta sebagian besar tergolong pengetahuan baik. Hal ini sejalan dengan penelitian Hidayati, Salawati dan Istiana (2015) yang menyatakan bahwa metode demonstrasi lebih mudah untuk menunjukkan pengertian, ide, dan prosedur tentang suatu hal yang pernah dipersiapkan dengan teliti untuk memperlihatkan bagaimana cara melaksanakan suatu tindakan adegan dengan menggunakan alat peraga.

Hal ini sejalan dengan penelitian Siti Astuti,dkk (2016) bahwa terdapat pengaruh yang bermakna antara pelatihan pemberian ASI dengan pengetahuan. Sedangkan penelitian Bekti Yuniyanti (2017) menunjukkan kelompok yang mendapat dukungan KP-ASI sebagian besar memberikan ASI secara eksklusif sedangkan kelompok dengan pemberian leaflet hanya sebagian kecil yang memberikan ASI secara eksklusif 
Kegiatan pengabdian masyarakat ini mendapatkan respon positif dari bidan desa karena remaja, ibu hamil mau[pun ibu nifas serta bidan mendapatkan manfaat dari kegiatan ini. Manfaat bagi remaja yaitu adanya pengetahuan tentang ASI eksklusif dan kesempatan untuk ikut serta menjadi kader kesehatan. Manfaat bagi ibu hamil maupun ibu nifas yaitu mendapatkan pengetahuan tentang ASI eksklusif. Sedangkan bagi bidan desa manfaatnya yaitu mendapatkan bantuan upaya promotif tentang ASI eksklusif dari peran serta masyarakat terutama kader remaja peduli ASI sehingga diharapkan cakupan dan pemberian ASI eksklusif semakin meningkat.

\section{SIMPULAN DAN SARAN}

Setelah dilakukan pengabdian masyarakat telah terbentuk remaja peduli ASI di wilayah kelurahan Karangjati, pengetahuan remaja tentang ASI Eksklusif meningkat, peran remaja dalam menyampaikan informasi tentang ASI Eksklusif meningkat pula.

Kegiatan pemberdayaan remaja dalam pencapaian ASI Eksklusif dengan konsep pemberdayaan masyarakat dapat diterapkan sebagai model upaya penanggulangan masalahn gizi dan dikembangkan di wilayah lainnya.

Bagi sektor terkait dimohon untuk meningkatkan partisipasinya dalam pembinaan peningkatan capaian ASI Ekslusif melalui pemberdayaan masyarakat.

\section{UCAPAN TERIMAKASIH}

Terima kasih kami sampaikan kepada Poltekkes Kemenkes Semarang yang telah mendanai keberlangsungan kegiatan pengabdian masyarakat ini. Kepada Bapak Direktur, Ibu Kajur, Ibu Kaprodi, Teman dosen dan Karyawan, Mahasiswa, Bidan Desa serta Masyarakat yang telah membantu selesainya kegiatan pengabdian kepada masyarakat ini.

\section{DAFTAR PUSTAKA}

Adi, Ragil Catur. Herawati, Ida, dan Wiyono Joko. 2017. Hubungan Pengetahuan Remaja Putri Tentang Perubahan Fisik Pada Masa Pubertas Dengan Tingkat Stres. Program Studi Ilmu Keperawatan Fakultas Ilmu Kesehatan Universitas Tribhuwana Tunggadewi Malang. Nursing News Volume 2, Nomor 2.

Amatiria G dan Helmi Y. 2015. Studi Komparatif Pemberian ASI Ekslusif dan Pemberian PASI Terhadap Pertambahan Berat dan Panjang Badan pada Bayi Umur 6 Bulan. Poltekkes Tanjung Karang: Jurnal Keperawatan. Volume XI No.2 
Andira., Abdullah \& Sidik. 2012. Faktor-Faktor yang Berhubungan Dengan Kinerja Kader Dalam Kegiatan Posyandu di Kecamatan Bontobahari Kabupaten Bulukumba. (Jurnal Online), (http://repository.unhas.ac.id), diakses tanggal 11 Juni 2017

Azhar Arsyad. 2014. Media Pembelajaran. Jakarta: PT. Raja Grafindo Persada

BKKBN. 2011. Evaluasi Pembangunan Kependudukan dan KB BKKBN Provinsi Jawa Tengah. Jawa Tengah : BKKBN Provinsi

Depkes RI. 2002. Pedoman Teknis Pelayanan Kesehatan Dasar, Pelayanan Kesehatan Neonatal Esensial. Jakarta: Departemen Kesehatan RI Direktorat Jenderal Pembinaan Kesehatan Masyarakat dan Direktorat Bina Kesehatan Keluarga

Depkes R.I., 2008. Profil Kesehatan Indonesia. Jakarta: Departemen Kesehatan RI

Juliff D, Downie Jill and Pat Rapley. 2007. Knowledge and Attitudes of Secondary School Students to Breastfeeding. Neonatal Pediatric and Child Health Nursing. Vol.10 No.3

Karwati.2009. Asuhan Kebidanan V (Kebidanan Komunitas); Jakarta : Trans Info Media.

Kumalasari, Intan dan Iwan Andyantoro. 2012. Kesehatan Reproduksi untuk Mahasiswa Kebidanan dan Keperawatan. Jakarta : Salemba Medika

Lestari, Ika. 2013. Pengembangan Bahan Ajar Berbasis Kompetensi. Padang: Akademia Permata.

Mansur, Herawati \& Budiarti, Temu. 2014. Psikologi Ibu dan Anak. Jakarta: Salemba Medika

Marmi. 2011. Asuhan Kebidanan pada Masa Nifas "Peuperium Care”. Yogyakarta: Pustaka Pelajar

Maryunani, A, dkk. 2012. Asuhan Kegawatdaruratan dalam Kebidanan. Jakarta : Trans. Info Medika

Mubarak. 2010. Psikologi Remaja Perkembangan Peserta Didik. Jakarta: Bumi Aksara

Mubarak, W.I. 2012. Promosi kesehatan untuk kebidanan. Jakarta: salemba Medika.

Notoatmodjo, S. 2012. Promosi kesehatan dan Perilaku Kesehatan. Jakarta: Rineka cipta

Proverawati dan Rahmawati. 2010. Kapita Selekta ASI dan Menyusui. Yogyakarta: Nuha Medika

Rahmawati, Nur Indah, dkk. 2015. Pengaruh Penggunaan Buku Saku oleh Motivator terhadap Pengetahuan dan Keterampilan Motivator dalam Mengatasi Permasalahan Pemberian ASI 
(di Kecamatan Sewon Kabupaten Bantul. Sekolah Tinggi Ilmu Kesehatan Alma Ata Yogyakarta. JNKI, Vol. 3, No. 2, hal 64-70

Rohmaniah, S. N. Inayah. 2014. Gambaran Pengetahuan dan Sikap Remaja Putri dalam Menghadapi Perubahan Fisik Saat Pubertas di Pondok Pesantren Al-Baqiyatussholihat. Skripsi, Program Studi Ilmu Keperawatan, Fakultas Kedokteran dan Ilmu Kesehatan, Universitas Islam Negeri Syarif Hidayatullah. Jakarta.

Sadiman. 2011. Media Pendidikan, Pengertian, Pengembangan, dan Pemanfaatannya. Jakarta: PT. Raja Grafindo Persada.

Sarwono.S.W. 2011.Psikologi Remaja. Jakarta: PT Raja Grafindo Persada

Sulistyorini, C.I., Pebriyanti, S. dan Proverawati, A. (2010) Posyandu dan Desa Siaga Panduan untuk Bidan dan Kader. Nuha Medika, Yogyakarta

Swanson V, Power K, Kaur B, Carter H and Shepherd K. 2006. The impact of Knowledge and Social Influences on Adolescents' Breast-feeding Beliefs and Intentions. Public Health Nutrition: 9(3), 297-305

Trisnawati. 2015. Hubungan Pengetahuan, Sikap dan Budaya Akseptor KB terhadap Pemilihan Metode AKDR di Wilayah Kerja Puskesmas Anggadita Kabupaten Karawang. Jurnal Kebidanan volume 5 No. 1 Tahun 2015.

Walgito, Bimo. 2010. Sikap Manusia Teori dan Pengukurannya. Yogyakarta : Pustaka Pelajar.

Wawan, A dan Dewi, M. 2010. Teori dan Pengukuran Pengetahuan, Sikap danPerilaku Manusia.. Yogyakarta : Nuha Medika.

Widyastuti, Rahmawati, Purnamaningrum. 2009. Kesehatan Reproduksi. Jakarta : EGC

Yuniyanti B,Rofi'ah S, Rubiyanti . 2017. Poltekkes Kemenkes Semarang Prodi Kebidanan Magelang. JURNAL ILMIAH BIDAN, VOL.II, NO.1, 2017

Susanti I, 2016. Evaluasi Pembentukan Dan Pelatihan Kelompok Pendukung Asi Di Desa Mekargalih Dan Cipacing Kecamatan Jatinangor Kabupaten Sumedang. Departemen Ilmu Kesehatan Masyarakat. Epidemiologi dan Biostatistika Universitas Padjadjaran VOLUME 05 No. 02 Juni 2016 